第26回情報知識学フォーラム予稿

\title{
心理学の研究文化とオープンプラクティス
}

\section{Research culture and open practice in psychology}

\begin{abstract}
齊藤 智*
Satoru SAITO*

京都大学大学院教育学研究科

Graduate School of Education, Kyoto University

于606-8501 京都市左京区吉田本町

E-mail: saito.satoru.2z@kyoto-u.ac.jp

*連絡先著者 Corresponding Author

オープンプラクティスとは, オープンサイエンスの理念を実現するための個別具体的な研究実践 である. 心理学におけるオープンプラクティスには, オープンアクセスやオープンデータなどの研究 完了後に行われるものだけでなく, 事前登録, 事前審査, オープンレビュー, プレプリント公開など, 一連の研究活動の中に組み込まれているものも多い. それぞれにその目的と期待される役割がある ため, 独自の展開をたどっている側面があるが, 今後は, 複数のオープンプラクティスが, 1 つの゚ッ ケージとしてまとめられ, 研究の開始から成果の公開まで, ごく自然に透明性とアカウンタビリティが 高められるような仕組みが構築されていくことが望まれる.
\end{abstract}

Open practice is specific research action that is aimed to promote principles of open science. In psychology, there is a variety of such practices that are integral parts of a series of research activities, including preregistration, registered report, open review, and preprint upload, as well as those that are conducted after completion of the research, e.g., open access and open data. Each open practice is characterised by its specific goals and expected rules, and therefore, has been developed through its respective trajectory. It is desirable to combine a range of open practices within a coherent procedural package in order to advance transparency and accountability of scientific research.

キーワード: 心理学, 再現性危機, オープンサイエンス, オープンプラクティス, 研究文化

Keywords: psychology, replication crisis, open science, open practice, research culture

\section{1 はじめに}

$$
\text { オープンサイエンス (open science)の潮 }
$$

流は, さまざまな形で心理学にも強い影

響を与えている.オープンアクセス (open access) やオープンデータ (open data or public data-sharing) といった, 研究完了後 の情報公開・情報共有の拡大を求める夕 イプのオープンプラクティス (open 
practice) だけでな

$<$, 研究遂行中の諸 段階において, 各種 のオープンプラクテ イスが行われるよう になってきている （図1を参照）。これ らのうちいくつか は，公的資金によっ て行われた研究は, 公的に公開されなけ ればならないとい う，オープンサイエ ンスの一般的な考え 方に基づいて推進されている.

$$
\text { その一方で, いくつかのオープンプラ }
$$
クティスは，心理学および関連諸科学に 内在する研究文化を変容させるために必 然的に生まれてきた処方箋である[1]．心 理学におけるオープンサイエンスを考え る時，それぞれのオープンプラクティス が，心理学独自の問題とどのように関係 しているのかについて考慮する必要があ る.

以下では，まず，心理学においてオー プンサイエンスを駆動する力となった問 題を，その中でも特に深刻な問題であ る，再現性危機 (replication crisis) を中心 に紹介し，心理学がその原因に対してど のようにアプローチしているのかについ て説明する. 続いて，こうした心理学独 自の問題を色濃く反映しているオープン データの現状について報告する.

\section{2 再現性危機の背後にある問題}

心理学者がオープンサイエンスを強く
意識することになったいくつのきっかけ がある.オランダの社会心理学者が，捏 造したデータに基づいて50以上の論文を 出版していたことが，2011年8月に発覚 し，衝撃を持って報じられた[2]．捏造さ れたデータが出版され，長期間に亘って その不正が発見されなかったという事実 は, 心理学者に自らの研究プラクティス に疑念を抱かせることになった。また， 同じく2011年には，予知能力の存在を主 張する論文が実験データとともに権威あ る社会心理学の雑誌に掲載された[3]. こ の超能力論文については，翌年にはその 追試に失敗したという論文が出版されて いる[4]. 物理学の理論と整合しない現象 [5]が審査を経て出版されてしまったとい う事例は，心理学者に，「超能力を信じ るか，心理学の研究方法を疑うか」とい う選択を迫ることになった[6].

心理学の研究方法への疑念をさらに深 め，抜本的な改革を促すことになったの が，再現性危機である．2015年に杂誌 Scienceに報告された大規模な追試実験プ 
ロジェクトの結果は信じ難い（信じたく ない）ものであった。 心理学の中でも比 較的頑健な結果を報告していると考えら れていた認知心理学系の研究では, 結果 の再現に成功したのは， $50.0 \%$, 社会心理 学系の研究では，25.5\%だったのである [7]. 現在, 多くの再現研究が行われるよ うになり，直接的追試(direct replication)を 行った研究も雑誌論文として報告される ようになった．しかし，直接的追試がこ のように行われるようになったのは再現 性危機が叫ばれるようになってからであ る. 心理学に限らず, 研究の新奇性を追 求する研究文化の中では, 特に直接的な 追試は重視されず，実施しても主要な業 績とはみなされない。このことが, 研究 の再現性の低さから心理学者の目を逸ら してきた可能性がある.

再現性の低い研究が生まれてしまう原 因としては, 心理学研究の理論の弱さや [5], 問題のある研究プラクティス

(questionable research practices) の使用など [8], いくつかが指摘されている[6]. ここ では，特にオープンデータにも関わる， お蔵入り問題 (file drawer problem) と，こ の問題から引き起こされる出版バイアス (publication bias) を取り上げる.これら は, 心理学の研究文化に根付く構造的な 問題を反映しており，現時点でも根本的 には解決されていない. そして，これら こそがオープンプラクティスという処方 箋によって挑まれるべき問題であると考 えられる。

お蔵入り問題とは, 実施された研究の 結果が，何らかの理由によって公開され ず，データが埋蔵されてしまう事態を指 す。さまざまな理由が考えられるが，こ
こで問題となるのは, 研究の結果が仮説 を支持しない，あるいは統計的に有意な 結果が得られなかったという理由による データのお蔵入りである. 容易に想像で きるように，こうした理由によるデータ のお蔵入りは，仮説を支持する結果や統 計的に有意な結果が得られた場合にのみ 出版されるという出版バイアスを生じさ せることになる[6].

この出版バイアスの問題を具体的に考 えるため，仮想事例を用意してみた.

「同じテーマに関する10の研究が異なる 研究室で独立に行われた．統計的に有意 な効果を得なかった $8 つ の$ 研究室はその研 究の出版を諦め, 一方, 有意な効果を得 た2つの研究室は論文を執筆・投稿し, 採 択・掲載された。」ここには，研究上の 不正は何もない. しかし, 出版バイアス によって，真実とは異なる結果が世に出 てしまうことになる．次の仮想事例[6]は じうだろうか。「ある科学者が10の実験 を実施し，それから望んだ仮説と一致す る，統計的に有意な結果をもたらした2つ のみを選んで論文にした。」ここには明 らかな研究不正があり, 出版された結果 は真実からは程遠い。前者は，悪意のな い出版バイアスの事例であり, 後者は, 研究不正の事例である. しかし, それら が引き起こす研究上の問題, すなわち再 現され得ない研究結果が世に出てしまう という問題は同じなのである.

\section{3 再現性危機へのアプローチ}

お蔵入り問題，およびそこから派生す る出版バイアスを発生させないために は, 当然ながら, データの埋蔵を防ぐこ 
とが肝要である.

そのための1つの方法が，事前登録 (preregistration)の推奨である（図1参 照）。研究者は, 実験や調查の計画が完 成した時点で, データ収集の前に, OSF (Open Science Framework)などのサービス を用いて，仮説や方法，分析の計画など の研究の内容を, 前もって詳細に登録し ておく。事前登録は，HARKing

(Hypothesizing After the Results are Known) などの問題のある研究プラクティスを防 ぐために導入されている側面もあるが 6 , 8], 実施された研究が出版されない場合に その研究が完全に消失してしまうことを 防ぐことにも役立つ.

ただし，仮説を支持せず，統計的にも 有意ではないどのような研究でも, 実施 された場合には科学的な事実としてその データが考慮されなければならないのか どうかについては疑問がある。お蔵入り となった研究がお蔵入りとなる理由には 様々なものがあり [9]，例えば，実験方法 の瑕疪が研究を台無しにしている場合な どは，むしろそのデータは世に出ない方 がよいかもしれない（そのようなケース には反面教師的な教育的意義があるかも しれないが）。

事前審査に基づいた研究報告 (registered report）とは，実験や調査を実施する前 に, 理論的価值や方法, 分析計画が審査 され, IPA (In-Principle Acceptance) という 状態となってから, 実験や調査が開始さ れる論文のカテゴリである（図1参照）。 実験・調査の終了後に結果及び考察を含 めた完全な原稿が再度投稿され審査され るが，結果の内容にかかわらず当該の研 究は採択される。この方法であれば，一
定の水準に達した実験や調査しか行われ ないため，その結果がどのようなもので あっても，それはそれとして価值のある データを残すことになる。 また，結果に 依存した形でのデータのお蔵入りや, 出 版バイアスを防ぐことにも一定程度は貢 献する. 事前審査報告という論文カテゴ リの導入は,さらに，統計的に有意でな ければ，実験結果が出版できない（その 結果，それまでの努力が無駄になる）と いうような研究の博打化を避ける力があ るため, 研究者が被るリスクを低減し, 研究の健全な発展にも寄与すると期待さ れている[6].

2013年に雑誌Cortexによって開始された 事前審查報告という審査制度は，同時期 から急速に他の雑誌にも広がり, 現在で は，その数の確認が困難なほど増えてい る、ただし，この仕組みにはまだ改善の 余地はあり，日本国内においては試験的 な導入とその議論の段階である[10].

\section{4 心理学におけるオープンデータ}

心理学におけるオープンプラクティス には，出版された論文のオープンアクセ スやオープンデータに留まらず，研究の プロセスそのものの透明性を高めること を目的としている点に特徵がある。例え ば，出版バイアスを防ぐためには，ネガ ティブデータもまた出版できる研究文化 を涵養する必要があるとともに, 出版さ れなかったデータへのアクセスも可能に なるような仕組みも求められるのかもし れない。 
一方で，再現性 危機は，出版され た研究のデータの 公開という，標準 的なオープンデー タも推進すること になった。最後 に，心理学におけ るオープンデータ の現状と問題点を 紹介する。

ここ1,2年の間 に, 心理学の主要 雑誌と呼ばれる雑誌においては，論文採 択後，場合によっては論文投稿時にデー 夕を公開することを求めることが一般的 になってきた。したがって，今後は順 次，データが公開されていくことになる と考えられる．このことは，数年前 （2014-2017）には，オープンデータを採用 している論文の割合が，4\%に満たなかっ たことを考えると $[11]$, 大きく急激な変 化であると言えよう。図2に示されている ように，2014年-2015年と2016年-2017年 の間にもデータを公開している論文の割 合（データ公開率）が大幅に増加してい ることがわかる．ただし，データ公開率 は雑誌によって大きく異なり，オープン データがほとんど進まなかった雑誌があ ることも事実である。

現在指摘されているオープンデータの 問題は，データの公開率の低さよりも， 公開されているデータの質の低さである [11]．データの完全性（completeness） とデータの再利用可能性 (reusability) の低さが特に深刻である。データに久損 があるなどして，結果が再現できるだけ
の十分なデータが公開されていない研究 が数多くある（完全性の問題）。また, メタデータ（データ記述及び文脈情報） の欠如がデータの解釈を困難にし，デー タ形式の不統一（例えばSPSSのフォーマ ット）がデータの利用を妨げている（再 利用可能性の問題）。さらに, データの 保管場所についてもその永続性という観 点からリスクが指摘されている. 例え ば，大学のサーバーにデータを保管して いる場合, 将来的にはサーバーのアドレ スが変更され，公開したURLにアクセスで きなくなる可能性がある。「情報知識学 会誌執筆要領」には，「URLを参照しても よいが，移動または削除される可能性が あるので, 極力避ける.」と，この問題 を回避するための指南となる記述があ る. 心理学者が見習うべきプラクティス である。

\section{5 オープンプラクティスの統合へ}

さまざまなオープンプラクティスに は，それぞれにその目的と想定される役 
割がある．再現性危機に駆動されたプラ クティスもあれば，研究のアカウンタビ リティに基づくものもある. そのため, 個々のオープンプラクティスは，それぞ れが独自のプラットフォームを持ち，あ る特定のコミュニティにおいて発達して いる。しかし，これらは全て一連の研究 活動の一部である（図1を参照）。事前登 録の情報も，事前審査の審査結果も，分 析のプロトコルと分析結果も, プレプリ ント原稿も, そして公刊された論文に付 随して公開されるデータも，1つの研究プ ロジェクトから生まれてくる. 1研究者と しては，複数のオープンプラクティス が，1つのパッケージとしてまとめられ， 研究の開始から研究成果の公開まで，ご く自然に透明性が高められるような仕組 みが構築されていくことを期待してい る.

\section{謝辞}

本報告のために必要な資料収集は，国際 共同研究加速基金（国際共同研究強化B） （課題番号：18KK0069）の補助を受けて行 われた。

\section{参考文献}

[1] Bishop, Dorothy. V. M.: "The psychology of experimental psychologists: Overcoming cognitive constraints to improve research: The 47th Sir Frederic Bartlett Lecture", Quarterly Journal of Experimental Psychology, Vol.73, No.1, pp.1-19, 2020.

[2] Callaway, Ewen: "Report finds massive fraud at Dutch universities", Nature, Vol.479,
No.7371, p.15, 2011.

[3] Bem, Daryl J.: "Feeling the future:

Experimental evidence for anomalous retroactive influences on cognition and affect", Journal of Personality and Social Psychology, Vol.100, No.3, pp.407-425, 2011.

[4] Ritchie, Stuart J.; Wiseman, Richard; French, Christopher C.: "Failing the future: Three unsuccessful attempts to replicate Bem's 'retroactive facilitation of recall' effect", PLoS ONE, Vol.7, No.3, e33423, 2012.

[5] 高橋康介：「新しく古い心理学のかた ち」, 心理学評論,Vol.62, No.3, pp.304-310, 2019.

[6] Chambers, Chris（大塚紳一郎訳）： 「心理学の7つの大罪」, みすず書房, 330p., 2019.

[7] Open Science Collaboration: "Estimating reproducibility of psychological science", Science, Vol.349, No.6251, pp.aac4716-1 aac4716-8, 2015.

[8] 池田功毅; 平石 界：「心理学におけ る再現性危機 : 問題の構造と解決策」, 心理学評論,Vol.59, No.1, pp.3-14, 2016.

[9] Lishner, David A.: "Sorting the file drawer: A typology for describing unpublished studies", Perspectives on Psychological Science, DOI: 10.1126/science.aac4716 [10] 三浦麻子：「『事前登録の事前審 査』経過報告と所感」, 心理学評 論,Vol.62, No.3, pp.272-280, 2019. [11] Towse, John N., Ellis, David A., \& Towse, Andrea S.: “Opening Pandora's Box: Peeking inside Psychology's data sharing practices, and seven recommendations for change”, Behavior Research Methods, Vol.53, No.4, 1455-1468, 2021. 